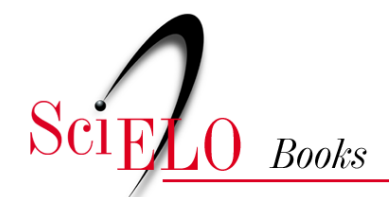

\title{
Capítulo 4 - Análise inferencial
}

\author{
Ivan Filipe de Almeida Lopes Fernandes
}

\section{SciELO Books / SciELO Livros / SciELO Libros}

FERNANDES, I.F.A.L. Análise inferencial. In: A democracia reduz a desigualdade econômica? Um estudo sobre as possibilidades de construção de uma sociedade mais igual por meio da democracia [online]. São Bernardo do Campo, SP: Editora UFABC, 2017, pp. 175-221. ISBN: 978-85-68576-79-3. https://doi.org/10.7476/9788568576793.0005.

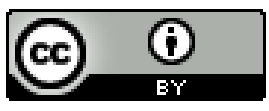

All the contents of this work, except where otherwise noted, is licensed under a Creative Commons Attribution 4.0 $\underline{\text { International license. }}$

Todo o conteúdo deste trabalho, exceto quando houver ressalva, é publicado sob a licença Creative Commons Atribição $\underline{4.0}$.

Todo el contenido de esta obra, excepto donde se indique lo contrario, está bajo licencia de la licencia $\underline{\text { Creative }}$ Commons Reconocimento 4.0. 


\section{Capítulo 4}

\section{Análise inferencial}

\subsection{Identificação de democracia}

O objetivo deste capítulo é destrinchar empiricamente a relação entre democracia e desigualdade conforme os problemas teóricos e questões metodológicas apresentados nos capítulos anteriores. Em primeiro lugar, temos como objetivo teórico-empírico principal discutir a questão se a democracia seria ou não uma ferramenta de redução da desigualdade econômica. Conforme já exposto anteriormente, tomamos como ponto de partida uma definição minimalista de democracia, compreendida apenas como uma forma competitiva de escolha por parte dos cidadãos das principais lideranças políticas. E, dada esta natureza competitiva da democracia, propusemos no capítulo 2 a hipótese de que a desigualdade tornar-se-ia um assunto relevante na competição eleitoral apenas nas sociedades mais desiguais: exatamente nas quais a desigualdade econômica estimula o surgimento de uma demanda por distribuição por parte da cidadania e também um interesse dos partidos que competem pelo poder político em ofertar políticas redistributivas, criando na sociedade a ideia de que a desigualdade seria resultado de injustiça e desequilíbrio social.

Para responder a esta questão, utilizamos como método mais adequado para a estimação dos efeitos heterogêneos 
da democracia sobre a desigualdade o framework de regressão quantílica, que permite a estimação dos efeitos da democracia ao longo de diferentes pontos da distribuição de desigualdade econômica entre os países. Para isto estimamos inúmeras regressões para verificar o efeito da democracia em diferentes pontos da distribuição de desigualdade econômica.

Um primeiro desafio metodológico a ser superado é a possível causalidade reversa entre democracia e desigualdade. Na literatura sobre os processos de democratização, a existência de desigualdade econômica dentro de determinada comunidade política dificulta as chances de sucesso do projeto democrático (BOIX, 2003; ACEMOGLU; ROBINSON, 2006; HOULE, 2009) ou na revisão proposta por Ansell e Samuels (2014), o surgimento de uma elite econômica independente tem impacto positivo no índice de GINI e ao mesmo tempo aumenta a probabilidade de democratização de um país.

Para resolver este problema, utilizamos o método de estimação por variável instrumental. Conforme exposto no capítulo 2, adotamos três diferentes conjuntos de instrumentos para estimar o verdadeiro efeito da democracia sobre a desigualdade. O primeiro é composto de um conjunto de variáveis relacionadas aos processos de difusão de democracia. E o segundo é um instrumento relacionado à herança colonial britânica. Ambos os conjuntos não possuem uma natureza completamente exógena ao mundo da política. Já o terceiro conjunto é composto por variáveis que captam o posicionamento longitudinal de um país no planisfério. As duas variáveis utilizadas para captar esse fenômeno são por definição estritamente exógena à relação entre democracia e desigualdade, uma vez que o posicionamento longitudinal de um país é um dado independente de sua conformação política e social 
e também não existem estudos ou teorias, até onde pudemos verificar, que relacionem a longitude de um país com a sua desigualdade econômica.

Quadro 2 - Instrumentos de democracia

1) Instrumentos de Difusão:

a) Difusão mundial de democracia: número de democracia existentes no ano / número de países existentes no ano. [difmundo]

b) Difusão continental de democracia: número de democracia existentes no continente no ano / número de países existentes no continente no ano. [difcont]

c) Difusão subcontinental de democracia: número de democracia existentes no subcontinente no ano / número de países existentes no subcontinente no ano. [difregião]

d) Difusão ponderada de democracia: média simples das medidas (a); (b) e (c) [difpond1]

e) Difusão ponderada de democracia dado a relevância regional e continental do país: média de (a), (b) e (c), ponderada pelo peso territorial do país no continente e no subcontinente, respectivamente [difpond2]

2) Herança Britânica: indicador se o país possui herança britânica, incluindo o próprio Reino Unido e ex-colônias americanas e australianas, adaptado de (HADENIUS; TEORELL, 2005) [british]

3) Localização Longitudinal

a) Hemisférico Oriental: indicador se o país possui localização longitudinal ao oriente do meridiano $36^{\circ}$ (Turquia). [horiental]

b) Longitude: $\log$ da longitude de um país calculado por $105+$ longitude. [llong]

A intuição básica subjacente à abordagem instrumental é estimar o efeito da variável endógena (a independente com problema de causalidade reversa) democracia, usando uma variável exógena correlacionada apenas com a variável endógena e não com a variável dependente - desigualdade econômica, isolando, assim, os efeitos da primeira sobre a última. A validade da estimação por variável instrumental depende 
crucialmente da seleção de um instrumento adequado, que satisfaça os dois critérios: (a) ser correlacionado com a variável endógena; e (b) não possuir um efeito causal na variável dependente (ou, por extensão, no termo de erro da equação estimada). $\mathrm{O}$ atendimento a estes critérios implica que qualquer alteração na variável dependente que resulte de mudanças nos valores de um instrumento deve ser atribuída à variável endógena e, deste modo, livre da relação recíproca entre a variável dependente e a variável endógena (SAVUN; TIRONE, 2011). No Quadro 2 reapresentamos o Quadro 1 onde listamos os potenciais instrumentos selecionados.

Nas tabelas 8, 9 e 10 (p. 183, 185 e 188) apresentamos os coeficientes, erros padrões e os Testes $\mathrm{F}$ do $1^{\circ}$ passo de cada uma das regressões utilizando defasagens dos instrumentos de difusão e dos indicadores de herança britânica e de longitude ${ }^{91}$, de modo a apresentar quais são os instrumentos adequados para a análise inferencial da relação entre democracia e desigualdade. Na última linha apresentamos os testes $\mathrm{F}$ conjunto de todos os instrumentos presentes no modelo. Na Tabela 8 adotamos uma especificação com efeitos fixos continentais ${ }^{92}$, na Tabela 9 incluímos

\footnotetext{
91 Foram incluídas nas regressões as variáveis controles presentes no modelo final, além do indicador de democracia do CGV (demo). Essas variáveis foram detalhadas na Tabela 7: Abertura Econômica; Participação do Governo; Comércio Mundial; Globalização, Desenvolvimento (em formato quadrático); Urbanização; Escolarização. Além destas incluímos uma variável de tendência em forma quadrática e efeitos fixos continentais. Não apresentamos os efeitos das variáveis controles, pois no momento estamos interessados em verificar apenas se os instrumentos identificam a relação entre democracia e desigualdade. Obviamente a amostra do $1^{\circ}$ passo é limitada aos casos para os quais possuímos informações sobre desigualdade econômica mensurada pelo UTIP-EHII.

92 Os continentes são América; Europa e ex-URSS; África e Oriente Médio; Ásia; e Oceania.
} 
efeitos fixos continentais e temporais e, por fim, na Tabela 10 incluímos efeitos fixos regionais e temporais ${ }^{93}$.

A disposição das variáveis nas três tabelas é a mesma. $\mathrm{Na}$ coluna (1) apresentamos os efeitos dos instrumentos quando entram no $1^{\circ}$ passo como única variável de identificação. Para tal foram rodadas regressões para cada um dos potenciais instrumentos. Na coluna (2) inserimos as mensurações puras de difusão regional, continental e mundial conjuntamente. $\mathrm{Na}$ coluna (3) analisamos conjuntamente os indicadores hemisféricos e de herança britânica, além da localização contínua da longitude do país. Observando os resultados das três primeiras colunas, incluímos na coluna (4) apenas os instrumentos adequados para a análise empírica. Diante dos resultados deste modelo, apresentamos na coluna (5) os instrumentos que identificam fortemente democracia e que, portanto, são mantidos nas análises daquela especificação ${ }^{94}$.

A análise cuidadosa do $1^{\circ}$ passo é fundamental, pois conforme já demonstrado na literatura econométrica, quando os instrumentos estão fracamente correlacionados com os regressores endógenos - não atendem ao critério (a) para a validade do instrumento - os resultados convencionais assintóticos falham, mesmo na presença de amostras grandes (STAIGER; STOCK, 1997).

Como apontado por Bound, Jaeger e Baker a "cura" para a existência de causalidade reversa na relação de interesse pode

\footnotetext{
93 As regiões são América do Norte e Central; Am. do Sul; Europa Ocidental; Leste Europeu e ex-URSS; África do Norte e Oriente Médio; África Subsaariana; Extremo Oriente; Ásia do Sul; Sudeste Asiático; e Oceania.

94 Como as variáveis de democracia e difusão estão com defasagens, perdemos 30 países-anos nos modelos que incluem alguma variável de difusão. Assim, o $\mathrm{N}$ dos modelos sem difusão é 3811 e o $\mathrm{N}$ dos modelos com difusão é sempre 3781. Na estimação da relação heterogênea entre democracia e desigualdade, democracia está defasada em um e difusão de democracia em dois anos.
} 
ser "pior que a doença" na presença de instrumentos fracos. Posto isto, nos próximos parágrafos analisamos os resultados do $1^{\circ}$ estágio em seus pormenores, observando as diversas formas nas quais podemos usar o conjunto de 08 instrumentos apresentados no Quadro 2 e quais podem de fato identificar democracia, atendendo aos dois critérios exigidos pelo método (BOUND; JAEGER; BAKER, 1995).

Na coluna (1) da Tabela 8 observamos que nem todas as cinco mensurações de difusão configuram como instrumentos fortes de democracia. As variáveis de difusão na região difregião e difusão ponderada difpond1 são significantes à 95\% de confiança, enquanto difusão no mundo difmundo e difusão ponderada pela relevância territorial difpond2 são significantes apenas à 90\%. Por sua vez, difusão continental difcont não tem relação significante com democracia. A única variável de difusão com teste $\mathrm{F}$ superior à 10 é difregião ${ }^{95}$. Além do mais, um resultado muito interessante obtido na coluna (1) é o fato de que difusão mundial de democracia difmundo está negativa e significantemente relacionada com democracia. E os outros três instrumentos, o conjunto sobre a posição longitudinal llong e horiental e o indicador de herança colonial britânica british, nenhum é significante à $90 \% \mathrm{e}$ todos têm um teste $\mathrm{F}$ inferior à 2.70.

$\mathrm{Na}$ coluna (2) testamos em conjunto apenas as mensurações puras de difusão regional, continental e mundial da democracia. A primeira constatação é que, neste modelo, as variáveis agregadas em circunscrições geográficas mais elevadas

\footnotetext{
95 Staiger e Stock propõem como regra de bolso que em modelos que incluam apenas uma única variável endógena, os instrumentos são fracos se o Teste-F do $1^{\circ}$ estágio for menor do que 10 (STAIGER; STOCK, 1997).
} 
(continental e mundial) são negativa e significantemente associadas com democracia, enquanto apenas a variável difusão regional difregiao tem relação positiva com democracia a $99 \%$ de confiança. Além do mais, todos os três testes Fs melhoram, sendo que o teste da última variável atinge 16.02. Interessante observar ainda que o teste $\mathrm{F}$ do modelo completo com as três variáveis de difusão de democracia $(\mathrm{F}=5.80)$ é maior e mais significante do que o teste $\mathrm{F}$ do modelo que utiliza as variáveis resumo que ponderam a difusão nos três níveis geográficos, respectivamente $\mathrm{F}=5.43$ para difpond $1 \mathrm{e} F=3.51$ para difpond ${ }^{96}$.

Em consequência destes resultados, optamos como método de identificação da democracia a utilização das três variáveis puras de difusão difmundo, difcont e difregião e não as variáveis ponderadas. Além de termos um instrumento com teste F superior a 10, tal como defendido por Staiger e Stock (1997), a sumarização destas três medidas de difusão em difpond1 e difpond 2 tem menor poder de identificação do que a utilização conjunta das três variáveis. Além disso, outra justificativa desta escolha é a incapacidade de as variáveis ponderadas captarem os distintos efeitos da difusão de democracia em diferentes circunscrições geográficas, um resultado inesperado, mas consistente ao longo de todo este estudo, não importando as especificações apresentadas ${ }^{97}$.

\footnotetext{
$96 \mathrm{O} \mathrm{R}^{2}$ do modelo com as variáveis puras é maior também que os $\mathrm{R}^{2}$ dos modelos com as variáveis ponderadas difpond1 e difpond2. Os valores são, respectivamente, 0.5035 ; 0.4860 ; e 0.4828 .

${ }^{97}$ Interessante observar a movimentação dos sinais dos coeficientes de cada uma das variáveis de difusão. Indo em direção contrária às teorias sobre a difusão da democracia, encontramos um efeito negativo da expansão da democracia no mundo difmundo e no continente difcont sobre as chances de um país ser uma democracia nas colunas (1) e (2). Já a variável difusão de democracia na região difregião tem o sinal esperado em ambas colunas. Uma possível explicação
} 
Na coluna 3 incluímos as outras três variáveis instrumentais restantes em um único modelo. As duas variáveis longitudinais, o indicador hemisférico horiental e a longitude llong são significantes, a primeira a $90 \%$ e a segunda a $95 \%$. Contudo, curiosamente, seus sinais são invertidos. Enquanto ambas crescem no sentido do oriente, o indicador hemisférico dá indícios que o hemisfério ocidental é mais democrático que o oriental, mas a variável longitudinal indica que, controlado o efeito hemisférico, quanto mais no oriente um país está, mais democrático ele é. Este resultado permanece em todas as especificações testadas.

Já a variável "herança colonial britânica" não está associada com democracia, o que também é outro achado na contramão das expectativas. E mesmo se expandirmos a amostra para todos os países-anos para os quais temos dados para as variáveis controles, o resultado se mantém. De fato, a herança colonial britânica não parece ser um determinante da democracia. E tal resultado se repete em todos os modelos apresentados. Por conseguinte, british é descartado ao não se adequar ao primeiro dos dois critérios necessários para a identificação adequada de uma variável endógena por meio de um instrumento.

pode ser o fato que limitamos nossa análise a apenas aos países-anos que possuem informação sobre desigualdade econômica $(n=3811)$. Se a expandirmos a amostra para toda a população $(n=6439)$ para qual temos informações sobre as variáveis de controle, os sinais permanecem iguais. No modelo da coluna (2), as variáveis difmundo e difcont permanecem significantes e negativamente associados com democracia a $90 \%$ e $95 \%$ de confiança. E difregião também permaneça significante e positivamente relacionado à $99 \%$. Já nos modelos da coluna (1) difmundo torna-se positivo e insignificante, difcont permanece negativo e insignificante e difregião positivo e significante à $99 \%$. Concluindo, é possível perceber com os resultados apresentados que o fenômeno da difusão de democracia é muito mais complexo que o teorizado na literatura e constituí um campo aberto e que deve ser alvo de estudos mais aprofundados. 


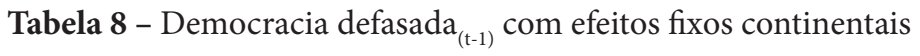

\begin{tabular}{|c|c|c|c|c|c|}
\hline & (1) & (2) & (3) & (4) & (5) \\
\hline \multirow[t]{2}{*}{ difmundo $_{(\mathrm{t}-2)}$} & $-0.550^{*}$ & $-0.522^{\star}$ & & -0.457 & \\
\hline & 0.307 & 0.288 & & 0.286 & \\
\hline F-test & $3.21^{*}$ & $3.29^{\star}$ & & 2.55 & \\
\hline \multirow{2}{*}{$\operatorname{difcont}_{(t-2)}$} & -0.139 & $-0.614^{\star \star}$ & & $-0.640^{\star *}$ & $-0.684^{\star *}$ \\
\hline & 0.224 & 0.252 & & 0.252 & 0.251 \\
\hline F-test & 0.38 & $5.92^{\star *}$ & & $6.47^{\star \star}$ & $7.40^{* *}$ \\
\hline \multirow{2}{*}{ difregião $_{(\mathrm{t}-2)}$} & $0.435^{\star \star}$ & $0.547^{\star * *}$ & & $0.580^{* * *}$ & $0.579^{\star * *}$ \\
\hline & 0.137 & 0.137 & & 0.137 & 0.137 \\
\hline \multirow{3}{*}{$\begin{array}{l}\text { F-test } \\
\text { difpond1 }\end{array}$} & $10.03^{* *}$ & $16.02^{\star * *}$ & & $17.87^{\star * *}$ & $17.94^{\star * *}$ \\
\hline & $0.747^{\star \star}$ & & & & \\
\hline & 0.321 & & & & \\
\hline F-test & $5.43^{\star \star}$ & & & & \\
\hline \multirow{2}{*}{ difpond2 $2_{(t-2)}$} & $0.219^{\star}$ & & & & \\
\hline & 0.117 & & & & \\
\hline F-test & $3.51^{\star}$ & & & & \\
\hline \multirow[t]{2}{*}{ horiental } & -0.176 & & $-0.214^{\star}$ & $-0.201^{\star}$ & $-0.201^{\star}$ \\
\hline & 0.108 & & 0.109 & 0.105 & 0.105 \\
\hline F-test & 2.63 & & $3.87^{\star}$ & $3.65^{\star}$ & $3.65^{\star}$ \\
\hline \multirow[t]{2}{*}{ british } & -0.005 & & 0.012 & & \\
\hline & 0.065 & & 0.066 & & \\
\hline F-test & 0.01 & & 0.03 & & \\
\hline \multirow[t]{2}{*}{ llong } & 0.137 & & $0.177^{\star *}$ & $0.208^{\star *}$ & $0.209^{* *}$ \\
\hline & 0.095 & & 0.082 & 0.076 & 0.076 \\
\hline F-test & 2.09 & & $4.66^{\star \star}$ & $7.48^{\star \star}$ & $7.54^{\star \star}$ \\
\hline $\mathrm{N}$ & 3781 & 3781 & 3811 & 3781 & 3781 \\
\hline \multicolumn{2}{|c|}{$\begin{array}{l}\text { F-test para todos } \\
\text { instrumentos }\end{array}$} & $5.80^{\star * \star}$ & $2.48^{\star}$ & $5.41^{\star * *}$ & $6.52^{\star * *}$ \\
\hline
\end{tabular}

Erros Padrões robustos e clusterizados por país.

Significância coeficientes e Testes F: ${ }^{*}<0,1 /^{* *}<0,05 /{ }^{* *}<0,01$

Na coluna (4) incluímos os dois conjuntos de instrumentos em um único modelo: as três mensurações de difusão de democracia e as variáveis longitudinais. Com exceção apenas da difmundo, todos outros instrumentos estão relaciona- 
dos com democracia. Difregião é positiva e significantemente associado com democracia à $99 \%$ de confiança, tendo apresentado um teste $\mathrm{F}$ superior à $10 \mathrm{em}$ todas as colunas, o que permite, portanto, uma identificação forte da variável democracia. Difcont e longitude estão associados à $95 \%$ e o indicador hemisférico à $90 \%$, sendo que o teste $\mathrm{F}$ de llong também se aproxima do limiar estabelecido por Staiger e Stock (1997). $\mathrm{O}$ teste $\mathrm{F}$ de todos os instrumentos é de 5.41.

Por fim, no modelo final de identificação - coluna (5) - mantemos apenas as variáveis da coluna (4) que foram significantes a no mínimo $90 \%$ de confiança ${ }^{98}$. Nesta primeira especificação com efeitos fixos continentais o modelo final é composto das seguintes variáveis: difcont, difregião, llong e horiental. O segundo é significante a $99 \%$, o primeiro e o terceiro a $95 \%$, e o quarto a $90 \%$, sendo o teste $\mathrm{F}$ do modelo da coluna (5) 6.52 ligeiramente superior ao F da coluna (4).

$\mathrm{Na}$ Tabela 9 reproduzimos a mesma análise incluindo além dos efeitos fixos para os cinco continentes, o controle de choques temporais exógenos (dummies de ano). Os resultados das variáveis de difusão são bastante semelhantes: difmundo e difcont continuam com sinais negativos enquanto difregião possui sinal positivo. E se repetirmos o modelo incluindo todos os dados para o qual temos informações das variáveis controles ( $\mathrm{N}=6439$ ), os resultados se repetem: difmundo e difcont são ambas negativamente relacionadas com democracia, mas só a primeira é significante a $99 \%$ de confiança enquanto a outra não atinge os limiares tradicionais de significância. Já difregião permanece com sinal positivo e fortemente significante.

\footnotetext{
98 Os testes empíricos demonstram que a inclusão de um instrumento de difusão que não tenha relação significativa com democracia reduz a eficiência da estimação e do método de identificação. Diante disso, optamos por excluí-los. Os testes utilizados para tal avaliação são os testes de Kleibergen-Paap de subidentificação e fraca identificação e a estatística J de Hansen sobreidentificação.
} 
Tabela 9 - Democracia defasada ${ }_{(\mathrm{t}-1)}$ com efeitos fixos continentais e temporais

\begin{tabular}{|c|c|c|c|c|c|}
\hline & (1) & (2) & (3) & (4) & (5) \\
\hline \multirow{2}{*}{ difmundo $_{(t-2)}$} & $-141.17^{\star * *}$ & $-141.46^{* * * *}$ & & $-140.44^{\star \star \star}$ & $-141.07^{\star * *}$ \\
\hline & 2.642 & 2.753 & & 2.803 & 2.742 \\
\hline F-test & $2854.64^{\star \star \star}$ & $2640.02^{\star * *}$ & & $2511.40^{\star \star \star}$ & $2647.55^{\star \star \star \star}$ \\
\hline \multirow{2}{*}{$\operatorname{difcont}_{(\mathrm{t}-2)}$} & -0.247 & $0.253^{* * *}$ & & $0.245^{\star * \star}$ & $0.287^{\star * *}$ \\
\hline & 0.238 & 0.067 & & 0.069 & 0.066 \\
\hline F-test & 1.08 & $14.03^{* * *}$ & & $12.46^{* * *}$ & $18.59^{\star * *}$ \\
\hline \multirow{2}{*}{ difregião $_{(t-2)}$} & $0.42^{\star *}$ & 0.037 & & 0.042 & \\
\hline & 0.142 & 0.026 & & 0.027 & \\
\hline F-test & $8.86^{* *}$ & 1.98 & & 2.50 & \\
\hline \multirow[t]{2}{*}{ difpond $_{(t-2)}$} & $0.720^{\star *}$ & & & & \\
\hline & 0.357 & & & & \\
\hline F-test & $4.07^{\star *}$ & & & & \\
\hline \multirow[t]{2}{*}{ difpond2 $_{(t-2)}$} & $0.209^{*}$ & & & & \\
\hline & 0.126 & & & & \\
\hline F-test & $2.77^{\star}$ & & & & \\
\hline \multirow[t]{2}{*}{ horiental } & $-0.174^{*}$ & & $-.212^{\star}$ & $-0.043^{\star *}$ & $-0.043^{\star *}$ \\
\hline & 0.109 & & 0.109 & 0.021 & 0.021 \\
\hline F-test & 2.54 & & $3.75^{\star}$ & $4.15^{\star \star}$ & $4.15^{\star \star}$ \\
\hline \multirow[t]{2}{*}{ british } & -0.006 & & 0.011 & & \\
\hline & 0.065 & & 0.067 & & \\
\hline F-test & 0.01 & & 0.03 & & \\
\hline \multirow[t]{2}{*}{ llong } & 0.137 & & $0.178^{\star *}$ & $0.024^{*}$ & 0.021 \\
\hline & 0.094 & & 0.082 & 0.013 & 0.013 \\
\hline F-test & 2.12 & & $4.68^{\star}$ & $3.29^{\star}$ & 2.39 \\
\hline $\mathrm{N}$ & 3781 & 3781 & 3811 & 3781 & 3781 \\
\hline $\begin{array}{l}\text { F-test para to } \\
\text { instrumentos }\end{array}$ & & $1067.35^{\star * *}$ & $2.45^{\star}$ & $723.22^{\star * \star}$ & $856.09^{\star * *}$ \\
\hline
\end{tabular}

Erros Padrões robustos e clusterizados por país.

Significância: ${ }^{*}<0,1 /^{* *}<0,05 / * * *<0,01$ 
Por outro lado, quando analisadas em conjunto, difmundo é a variável com maior poder explicativo, pois possui teste F muito superior a qualquer outro teste F da Tabela 9, incluindo a comparação com as variáveis ponderadas difpond1 e difpond2. Mais uma vez encontramos evidências que a melhor estratégia de identificação de democracia é a introdução conjunta das três variáveis de difusão puras. Ademais, quando difcont é um instrumento junto com as outras duas variáveis de difusão, ela também possui um teste $\mathrm{F}$ superior a 10.

O fator que determina o crescimento exponencial dos coeficientes e da significância da variável difmundo é a introdução das dummies de ano, uma vez que em cada ano o grau de difusão de democracia no mundo é por definição semelhante para todos os países. Desta forma, boa parte da variação deste dado foi capturada pelas dummies de ano e a pequena variação restante é sensivelmente relacionada com democracia ${ }^{99}$.

No que se refere aos outros três instrumentos, o mesmo resultado se repete. Os padrões encontrados na Tabela 8 não são alterados. A longitude e o indicador hemisférico são variáveis insignificantes quando instrumentos únicos. Contudo ao serem colocadas ao mesmo tempo no modelo, ambas atingem significância estatística a 95\% e 90\% de confiança, respectivamente,

\footnotetext{
99 Existe uma pequena diferença entre democracias e desigualdades em cada ano em todas as mensurações puras de difusão de democracia, pois quando um país é democrático, ele deve ser retirado tanto do denominador quanto do numerador da fórmula, enquanto quando um país é autoritário é retirado apenas do denominador. Supondo, por exemplo, que existam 50 países e 20 sejam democráticos. Para os países autoritários, o valor de difmundo é de 20/49 enquanto para os países democráticos esse valor é de 19/49. Esta diferença decorre da necessidade de se retirar o próprio país da contagem de difusão nas três circunscrições geográficas. Caso o próprio país fosse incluído no número de democracias e no número de ditaduras, as variáveis de difusão tornar-se-iam endógenas ao próprio regime político do país e deixariam de ser instrumentos adequados.
} 
enquanto o indicador de "herança colonial britânica" permanece insignificante em todos os modelos, resultado também repetido na Tabela 10.

No modelo da coluna (4), incluímos os dois conjuntos de instrumentos em um único modelo. Incluímos as três mensurações de difusão de democracia e também as variáveis longitudinais. As duas variáveis mais agregadas de difusão foram significantes e os testes Fs do modelo como um todo e das variáveis difmundo e difcont são superiores a 10 . Por outro lado, diferentemente do resultado da especificação apenas com efeitos fixos continentais, a variável difregião não é significante. Já as duas variáveis de longitude são significantes e possuem os mesmos sinais da Tabela 8 .

Posto isto, encontramos mais uma vez indícios de que a melhor forma de identificar a democracia é a utilização dos instrumentos de difusão e de localização longitudinal do país, não obstante para a especificação com efeitos fixos continentais e temporais utilizamos apenas difmundo e difcont como variáveis de difusão. O modelo final com todos os instrumentos é apresentado na coluna (5), onde llong está ligeiramente acima do limite de $90 \%$ de significância.

Por fim, na Tabela 10 reproduzimos os mesmos modelos, mas agora incorporamos efeitos fixos para os dez subcontinentes (ou regiões) além das dummies de ano, o que reduz de forma considerável a variabilidade dos dados. Os resultados continuam sendo mais robustos nesta especificação para a variável difmundo e difcont. Na primeira coluna da tabela, com exceção da variável de difmundo, todas as outras possuem relações estatisticamente insignificantes com democracia, o que é uma decorrência do fato que boa parte da variação dos dados é captado pelo conjunto de dummies temporais e regionais. 
Tabela 10 - Democracia defasada ${ }_{(\mathrm{t}-1)}$ com efeitos fixos regionais e temporais

\begin{tabular}{|c|c|c|c|c|c|}
\hline & (1) & (2) & (3) & (4) & (5) \\
\hline \multirow{2}{*}{ difmundo $_{(\mathrm{t}-2)}$} & $-140.65^{\star * *}$ & $-141.28^{\star * *}$ & & $-140.26^{* * *}$ & $-140.73^{* * *}$ \\
\hline & 2.55 & 2.695 & & 2.76 & 2.66 \\
\hline F-test & $3049.61^{\star * *}$ & $2748.84^{* * *}$ & & $2582.84^{* * *}$ & $2792.77^{\star * *}$ \\
\hline \multirow{2}{*}{$\operatorname{difcont}_{(\mathrm{t}-2)}$} & -0.317 & $0.221^{\star \star}$ & & $0.213^{\star *}$ & $0.297^{* * *}$ \\
\hline & 0.239 & 0.073 & & 0.072 & 0.65 \\
\hline F-test & 1.76 & $9.12^{\star \star}$ & & $8.77^{\star \star}$ & $20.80^{* * *}$ \\
\hline \multirow{2}{*}{ difregião $_{(t-2)}$} & 0.247 & 0.076 & & $0.09^{\star}$ & \\
\hline & 0.201 & 0.052 & & 0.507 & \\
\hline F-test & 1.50 & 2.09 & & $3.33^{\star}$ & \\
\hline \multirow[t]{2}{*}{ difpond1 $_{(\mathrm{t}-2)}$} & 0.084 & & & & \\
\hline & 0.373 & & & & \\
\hline F-test & 0.05 & & & & \\
\hline \multirow[t]{2}{*}{ difpond2 ${ }_{(\mathrm{t}-2)}$} & 0.054 & & & & \\
\hline & 0.137 & & & & \\
\hline F-test & 0.16 & & & & \\
\hline \multirow[t]{2}{*}{ horiental } & -0.158 & & -0.188 & $-0.051^{\star \star}$ & $-0.489^{\star *}$ \\
\hline & 0.119 & & 0.117 & 0.024 & 0.235 \\
\hline F-test & 1.75 & & 2.58 & $4.56^{\star *}$ & $4.31^{\star \star}$ \\
\hline \multirow[t]{2}{*}{ british } & -0.062 & & -0.059 & & \\
\hline & 0.065 & & 0.065 & & \\
\hline F-test & 0.91 & & 0.83 & & \\
\hline \multirow[t]{2}{*}{ llong } & 0.161 & & $0.209^{* *}$ & $0.032^{\star}$ & $0.295^{\star}$ \\
\hline & 0.107 & & 0.095 & 0.017 & 0.017 \\
\hline F-test & 2.23 & & $4.82^{\star \star}$ & $3.33^{\star \star}$ & $3.12^{\star}$ \\
\hline $\mathrm{N}$ & 3781 & 3781 & 3811 & 3781 & 3781 \\
\hline \multicolumn{2}{|c|}{ F-test for all instruments } & $5850.65^{\star * *}$ & $2.31^{\star}$ & $811.05^{\star * \star}$ & $904.53^{\star * *}$ \\
\hline
\end{tabular}

Erros Padrões robustos e clusterizados por país.

Significância: ${ }^{*}<0,1 /{ }^{* *}<0,05 / * * *<0,01$ 
Por outro lado, nos modelos da coluna (2) e da coluna (4) as outras variáveis puras de difusão, difcont e difregião recuperam a significância estatística e, inclusive, a primeira fica com um teste $\mathrm{F}$ muito próximo de 10. Já os outros dois conjuntos de variáveis apresentam um comportamento bem semelhante ao encontrado nos dados anteriores. As variáveis de longitude só ganham significância quando ambas fazem parte do modelo. Na coluna (3) longitude já é significante e na coluna (4) as duas o são (llong e horiental). Por sua vez, repetindo os resultados das duas tabelas anteriores, o indicador da herança colonial britânica, british, é não significante e inclusive mantém o sinal negativo.

Diante desses resultados semelhantes nas colunas (1), (2) e (3), optamos por incluir na identificação de democracia da coluna (4) as seguintes variáveis difmundo e difcont, difregião, llong e o indicador hemisférico horiental. O resultado final da Tabela 10 é o único no qual as três variáveis de difusão puras são significantes, ainda que difregião esteja no limite tolerável ao ter um p-valor de 0.90 . Posto isso, podemos verificar que nas três especificações a única variável presente em todos os modelos finais é difcont, apesar de ter trocado de sinal com a introdução das dummies de tempo. Difmundo, por sua vez, é sempre negativo, mas não significante na primeira especificação com apenas efeitos fixos continentais. Após a inclusão das dummies de ano torna-se fortemente associada com democracia em todas as especificações. E já a variável difregião é positiva em todos os modelos, mas confortavelmente significante apenas no primeiro modelo que não incorpora os choques temporais. As variáveis llong e horiental são significantes e bem estáveis em todos os modelos apresentados. Por fim, na coluna (5) da Tabela 10 apresentamos o modelo sem a 
variável difregião por razões que serão enunciadas nos próximos parágrafos ${ }^{100}$.

\section{$\mathscr{8}$}

Após apresentarmos extensamente a escolha das variáveis do primeiro estágio do modelo, discutimos alguns dos testes estatísticos que permitem verificar se os modelos finais de cada especificação identificam fortemente democracia ou não. Todas as estatísticas apresentadas nesta seção foram estimadas a partir de modelos lineares condicionais à média e em painel empilhado. Para mais informações sobre os testes de identificação por variável instrumental de regressores endógenos ver Baum, Schaffer e Stillman (2007).

No modelo com efeitos fixos continentais, apresentado na coluna 5 da Tabela 8, os testes Kleibergen-Paap rejeitam as hipóteses nula de subidentificação e de fraca identificação com F de, respectivamente, 9.85 e 6.52. E a estatística J de Hansen aceita a hipótese nula de sobreidentificação dos instrumentos à $10 \%$. Por fim, o teste de endogeneidade do indicador de democracia rejeita a hipótese nula de que esta variável possa ser tratada como exógena a 5\%.

Já no modelo com efeitos fixos continentais e temporais apresentado na coluna 5 da Tabela 9, a estatística J de Hansen só aceita a hipótese nula de sobreidentificação dos instrumentos a $10 \%$ e não a $5 \%$, ainda que melhore substancialmente a rejeição das hipóteses nulas de subidentificação e de fraca identificação nos testes Kleibergen-Paap para 59.51 e 856.01,

\footnotetext{
100 A inclusão desta variável faz com que o modelo rejeite a hipótese nula de sobreidentificação de todos os instrumentos da estatística J de Hansen.
} 
respectivamente. E o teste de endogeneidade do indicador de democracia aceita a hipótese nula de que esta variável seja exógena a mais de $40 \%$.

Finalmente, no modelo com efeitos fixos regionais e temporais, a estatística J de Hansen rejeita a hipótese nula de que o modelo é sobreidentificado a 5\% (p-valor: 0.04), além de os testes Kleibergen-Paap de subidentificação e de fraca identificação serem de 61.09 e 810.15 respectivamente. Devido a este resultado da estatística J de Hansen, optamos por excluir a variável difregiao da lista de instrumentos da especificação com efeitos fixos regionais e temporais pois era a única variável de difusão significante à $10 \%$, mas não a $5 \%$. Com isto, estatística J de Hansen aceita a hipótese nula de que o modelo é sobreidentificado à $4 \%$, além de os testes Kleibergen-Paap de subidentificação e de fraca identificação serem de 60.50 e 904.53, respectivamente. Logo, a especificação com efeitos fixos regionais e temporais terá a mesma lista de instrumentos da especificação com efeitos fixos continentais e temporais: difmundo, difcont, horiental e llong. Por fim, o teste de endogeneidade do indicador de democracia rejeita a hipótese nula de que esta variável possa ser tratada como exógena a $5 \%$.

Em todas as especificações do $1^{\circ}$ passo os instrumentos identificam fortemente democracia, atendendo ao primeiro critério da estimação por variável instrumental. Independentemente da especificação (com ou sem efeitos fixos temporais, regionais e/ou continentais) incluímos dois conjuntos de instrumentos - variáveis de difusão e de longitude dos países

\section{$\mathscr{8}$}

Como última etapa da análise da adequabilidade do método, também é importante avaliar a plausibilidade do segundo 
critério da estimação por variável instrumental. Isto é, a validade ou não da hipótese da restrição de exclusão. Não existe um teste específico para tal que seja semelhante aos testes que acabamos de avaliar para identificar quais instrumentos são fortemente correlacionados com a variável endógena. Contudo é possível verificar se, na presença de outros instrumentos fortes, a difusão democrática ou a longitude de um país é relacionada com a desigualdade econômica. Diante disso, por meio de uma especificação de modelos lineares condicionais à média e em painel empilhado, testamos se as variáveis de difusão e de longitude são relacionadas com a desigualdade econômica, após usarmos nossos próprios instrumentos para purificar democracia da potencial endogenia. $\mathrm{O}$ fato de termos sobreidentificado democracia em todos os modelos nos dá a flexibilidade necessária para testar a hipótese de restrição de exclusão por meio de múltiplos testes de Wald.

Fazemos isso de duas formas distintas. Na primeira testamos no $2^{\circ}$ passo do método cada variável instrumental isoladamente, enquanto as outras três permanecem como instrumentos no $1^{\circ}$ passo. E na segunda testamos os conjuntos de variáveis de difusão e de longitude separadamente. O exercício é aproveitar que em nossos modelos sobreidentificamos democracia, tal como comprovado pela estatística J de Hansen, e dessa forma podemos trabalhar com estas variáveis testando se algum dos instrumentos são covariáveis que afetam ou não desigualdade. Apresentamos os resultados deste exercício para as três especificações finais apresentadas nas colunas (5) das Tabelas 8, 9 e 10. 
Tabela 11 - Testes de endogeneidade

\begin{tabular}{|c|c|c|c|}
\hline \multicolumn{4}{|c|}{ Potenciais Instrumentos como Covariável Única no $2^{\circ}$ passo. } \\
\hline & $\begin{array}{l}\text { Efeitos Fixos } \\
\text { Continentais }\end{array}$ & $\begin{array}{c}\text { Efeitos Fixos } \\
\text { Continentais e } \\
\text { Temporais }\end{array}$ & $\begin{array}{c}\text { Efeitos Fixos } \\
\text { Regionais e } \\
\text { Temporais }\end{array}$ \\
\hline \multirow[t]{2}{*}{ difmundo $_{(\mathrm{t}-2)}$} & - & 7.347 & 65.895 \\
\hline & - & 20.358 & 325.651 \\
\hline \multirow{2}{*}{$\operatorname{difcont}_{(\mathrm{t}-2)}$} & 2.968 & 1.822 & 0.742 \\
\hline & 2.675 & 2.504 & 2.408 \\
\hline \multirow{2}{*}{ difregiao $_{(\mathrm{t}-2)}$} & 2.288 & - & - \\
\hline & 1.850 & - & - \\
\hline \multirow[t]{2}{*}{ horiental } & 2.375 & 0.990 & 0.909 \\
\hline & 1.938 & 1.255 & 1.297 \\
\hline \multirow[t]{2}{*}{ llong } & 1.122 & $1.722^{\star *}$ & 1.423 \\
\hline & 1.231 & 0.743 & 2.979 \\
\hline \multicolumn{4}{|c|}{ Potenciais Instrumentos como Covariáveis Conjuntas no $2^{\circ}$ passo. } \\
\hline \multirow{2}{*}{ difmundo $_{(\mathrm{t}-2)}$} & - & -12.352 & 0.000 \\
\hline & & 13.141 & 26.296 \\
\hline \multirow{2}{*}{$\operatorname{difcont}_{(\mathrm{t}-2)}$} & 0.703 & 1.831 & 0.710 \\
\hline & 4.204 & 2.496 & 2.396 \\
\hline \multirow{2}{*}{ difregião $_{(\mathrm{t}-2)}$} & 2.069 & - & - \\
\hline & 2.780 & - & - \\
\hline \multirow[t]{2}{*}{ horiental } & 2.254 & 0.604 & 0.666 \\
\hline & 1.944 & 1.243 & 1.278 \\
\hline \multirow[t]{2}{*}{ llong } & 0.246 & $1.633^{\star \star}$ & 1.253 \\
\hline & 1.340 & 0.705 & 0.971 \\
\hline $\mathrm{N}$ & 3781 & 3781 & 3781 \\
\hline
\end{tabular}

Erros Padrões robustos e clusterizados por país.

Significância: ${ }^{*}<0,1 /^{* *}<0,05 / * * *<0,01$ 
Conforme podemos ver na Tabela 11, o resultado das especificações que controlam para efeitos continentais e efeitos regionais temporais indica que os instrumentos não sofrem de endogeneidade. Já a especificação de efeitos fixos continentais e temporais tem um de seus instrumentos relacionados com desigualdade econômica - o posicionamento longitudinal llong

No primeiro modelo, todas as variáveis instrumentais são insignificantes quando inseridas como covariáveis do $2^{\circ}$ passo. Quando inseridas isoladamente, os menores p-valores são das variáveis difregiao e horiental (p-valor: 0.22 ) e os outros são de 0.26 para difcont e 0.36 para llong e quando inseridos em conjunto com a outra variável do grupo, o menor p-valor é de horiental (p-valor: 0.25), enquanto os outros valores são maiores: difregião -0.46 ; llong -0.85 ; e difcont - 0.87. No segundo modelo a variável llong tem efeito significativo sobre desigualdade econômica tanto quando inserida isoladamente como covariável como quando inserida junto com a outra variável de longitude. Posto isto, o uso destas quatro variáveis instrumentais é inadequado na especificação com efeito fixo continental e temporal. Diante de tal fato, optamos por rever o resultado da Tabela 9 e propomos como instrumentos finais de identificação de democracia apenas difmundo, difcont $\mathrm{e}$ horiental ${ }^{101}$. Finalmente, no terceiro modelo, no qual

101 O modelo final para esta especificação elimina, consequentemente, llong do rol de instrumentos. O resultado final do $1^{\circ}$ passo indica que os três instrumentos restantes são significantes: difmundo e difcont à $1 \%$ e horiental à $10 \%$. Neste novo modelo a estatística J de Hansen passa a aceitar a hipótese nula de sobreidentificação dos instrumentos a mais de 35\% e os resultados dos testes de subidentificação e de fraca identificação permanecem bastante satisfatórios; 59.03 e 1068.7, respectivamente. Por fim, nos testes de endogeneidade nenhum dos instrumentos é um determinante de desigualdade econômica, seja entrando 
incluímos efeitos fixos regionais e temporais, os quatro instrumentos são insignificantes em todos os modelos. Os p-valores, isolados e em conjunto respectivamente, são: para difmundo: 0.84 e 1.00; para difcont: 0.75 e 77; para horiental 0.49 e 0.60 ; e, finalmente, para llong: 0.63 e 0.20 .

Desta forma, finalizamos essa seção concluindo que o método de estimação da relação de democracia sobre a desigualdade econômica por meio de variáveis instrumentais de difusão e de longitude é apropriado. Ambos os critérios para a validade de um instrumento são atendidos. Os conjuntos de instrumentos identificam adequadamente a variável endógena, pois além de estarem fortemente relacionada com a variável endógena, não estão correlacionadas com a variável dependente e, por consequência, com o termo de erro $\boldsymbol{\varepsilon}_{\text {it }}$ do $2^{\circ}$ passo (hipótese de restrição de exclusão).

\subsection{Democracia e desigualdade econômica}

O segundo desafio metodológico é a estimação dos efeitos heterogêneos da democracia sobre a desigualdade econômica. Conforme expusemos anteriormente, o método mais adequado para responder a essa questão é a regressão quantílica apresentada no Capítulo 2. Posto isso, o único ponto a ser esclarecido antes de começarmos a expor os achados é o formato do resultado apresentado no output do modelo. Na realidade, tradicionalmente, os modelos de regressão quantílica são apresentados por meio de um output gráfico. Isto porque a regressão quantílica é usada como ferramenta

como covariável única ou como covariável conjunta no $2^{\circ}$ passo da equação. 
tradicional de estimação dos efeitos heterogêneos de uma variável independente sobre uma variável dependente contínua e para o tal é necessário estimar inúmeras regressões ao longo dos diferentes quantis condicionais da distribuição da variável dependente.

Os resultados da regressão quantílica são de fato o resultado de inúmeras regressões semelhantes, que variam apenas em relação $\tau$-ésimo quantil condicionado. Isto porque, por exemplo, para estimar os efeitos ao longo dos 9 diferentes decis de uma distribuição é necessário estimar nove regressões distintas que variam entre os $\tau$ de $\tau=0.1$ a $\tau=0.9$. Por outro lado, apesar dessa especificidade do método, a interpretação dos efeitos é semelhante às interpretações dos coeficientes das regressões lineares por MQO. E a opção do output gráfico tem como fundamento a maior facilidade para analisar a heterogeneidade dos efeitos da democracia sobre a desigualdade econômica do que a apresentação de uma série de tabelas de regressão com o mesmo conjunto de variáveis e diferentes apenas em relação aos quantis condicionais $\tau^{102}$.

\footnotetext{
102 Ademais, tal como explicitamos anteriormente, a regressão quantílica é utilizada no $2^{\circ}$ passo da estimação por variável instrumental. Os pormenores do $1^{\circ}$ passo foram apresentados na seção anterior e por isso podemos considerar que a variável independente de interesse dos modelos quantílicos é uma nova variável independente de democracia [demo], purificada - teoricamente - dos problemas de causalidade reversa.
} 


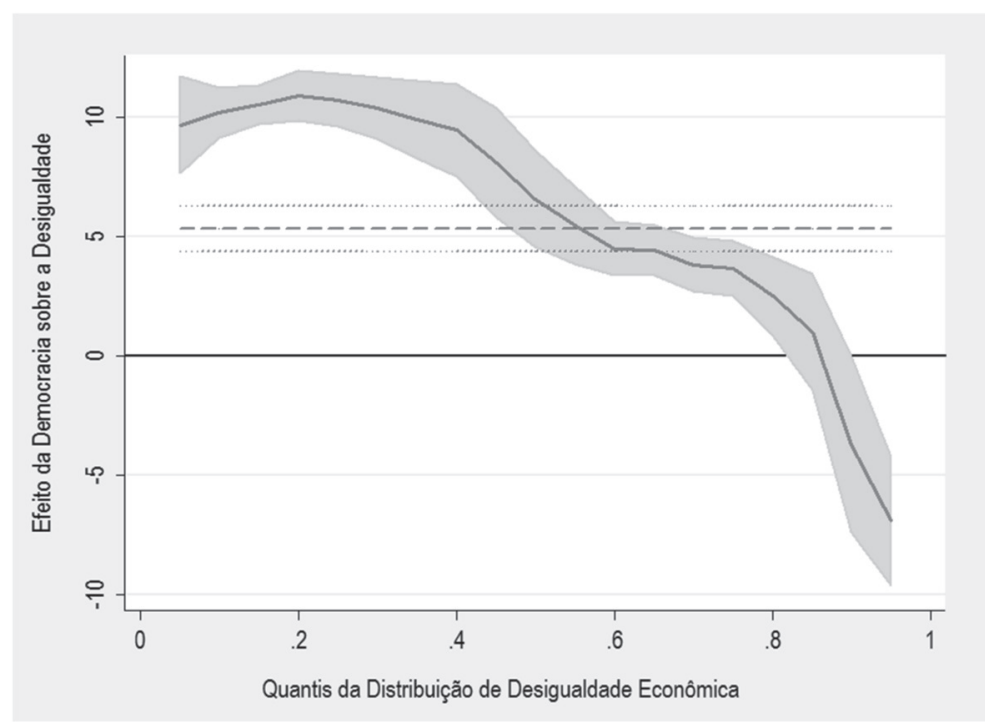

Gráfico 14 - Efeitos heterogêneos da democracia sobre a desigualdade econômica - efeitos fixos continentais Fonte: CGV e UTIP-EHII

$\mathrm{Na}$ série de gráficos que apresentamos mantemos um padrão uniforme de exposição dos dados. No eixo horizontal estão dispostos os quantis da distribuição de desigualdade econômica entre os países-anos, estando à esquerda os países-anos mais iguais e à direita os países-anos mais desiguais. Cada quantil refere-se à posição do caso na distribuição. O quantil 0.1 indica os casos que dividem os $10 \%$ anos/países mais iguais dos outros $90 \%$ entre 1963 e 2008 . Já o intervalo entre o quantil 0.4 e 0.6 abrange os $20 \%$ de casos localizados exatamente no centro da distribuição da desigualdade. E o quantil 0.9 indica os casos que dividem os $10 \%$ anos-países mais desiguais do restante $90 \%$ da amostra. No eixo vertical encontramos os efeitos estimados da democracia sobre a 
desigualdade em cada um dos quantis do eixo horizontal. Efeitos negativos indicam que a democracia possui uma relação inversa com a desigualdade: quanto mais democrático menos desigual. Já efeitos positivos indicam que a democracia possui uma relação de mesma direção: quanto mais democrático, mais desigual ${ }^{103}$.

Além dos efeitos heterogêneos da democracia que são apresentados na reta contínua, também indicamos em cinza os intervalos de confiança de cada um dos pontos estimados, todos condicionados no quantil de desigualdade. Estimamos os intervalos de confiança a $90 \%$ por meio do método de bootstrap de forma a tornar válida as inferências causais realizadas.

Do mesmo modo, apresentamos uma linha horizontal tracejada que indica o resultado de uma regressão em MQO e seu respectivo intervalo de confiança ${ }^{104}$. Além das curvas estimadas, inserimos em todos gráficos uma linha horizontal de referência que assinala o limite do efeito nulo de democracia. Esta linha (preta contínua e mais fina) tem como função separar os quantis nos quais os efeitos da democracia são positivos dos quantis onde os efeitos são negativos.

No conjunto de gráficos apresentamos diversos modelos de regressão quantílica em diferentes especificações, que

\footnotetext{
103 O impacto negativo da democracia sobre a desigualdade econômica é definido do ponto de vista estatístico, o que significa que a democracia e a desigualdade variam inversamente: isto é, quanto maior uma, menor a outra. Os termos impactos positivo e negativo estão sendo utilizados segundo este prisma de covariação estatística e nunca segundo um ponto de vista normativo, no qual o efeito da democracia seria bom (positivo) quando reduzisse a desigualdade econômica.

104 Na regressão de MQO estimamos o efeito médio da democracia sobre a desigualdade econômica. Obviamente este modelo, embora bastante difundido, não é o adequado para o estudo de nosso problema de pesquisa, uma vez que não permite a estimação dos efeitos da desigualdade em diferentes pontos da distribuição. E esta é a razão pela qual em todos os gráficos o resultado do modelo de MQO é uma reta paralela ao eixo horizontal.
} 
variam de acordo com os dados de democracia e desigualdade e entre os diferentes efeitos fixos inseridos. Nesta segunda seção do capítulo utilizamos os dados do CGV para medir democracia e do EHII para a desigualdade econômica. No próximo capítulo analisamos a relação usando os outros dados de desigualdade e democracia apresentados no capítulo 3. Em todos os modelos incluímos o mesmo vetor de variáveis controles citados na primeira nota de rodapé deste capítulo e na Tabela 7 do capítulo 3.

O Gráfico 14 (p. 197) apresenta a relação entre democracia e desigualdade na especificação com efeitos fixos continentais, utilizando os quatro instrumentos listados na Tabela 8. Neste gráfico fica claro que os efeitos da democracia sobre a desigualdade são fundamentalmente heterogêneos e o suposto sobre a homogeneidade dos efeitos é equivocado. O Gráfico 14 não deixa dúvidas de que os resultados apresentados por modelos lineares condicionais à média (MQO) - a reta horizontal tracejada - que no caso indicam que a democracia está positivamente associada com a desigualdade, refletem de maneira inadequada e reduzem em muito a complexidade da relação entre democracia e desigualdade. Por outro lado, é interessante notar como a regressão de MQO é de fato um sumário da relação média entre desigualdade e democracia, indicando um efeito médio e positivo da democracia em torno de 5.3 pontos de GINI. Contudo, o custo desta sumarização é a inflexibilidade para captar os pormenores de como o contexto socioeconômico no qual opera a democracia afeta os efeitos do regime político sobre a desigualdade.

Os efeitos da democracia só se tornam negativos ao final da distribuição, mais especificamente nos $13 \%$ países-anos mais desiguais durante todo o período analisado, justamente 
os países-anos nos quais é muito maior a probabilidade do surgimento de uma demanda por redistribuição no seio da cidadania e onde o cálculo do custo benefício da adoção de plataforma eleitoral e políticas públicas que foquem esse problema pelos partidos é mais favorável. Já nos primeiros $40 \%$ dos países-anos mais iguais de toda a amostra (os quatro primeiros decis da distribuição), existe um efeito um tanto homogênea e estável da democracia sobre a desigualdade, mais ou menos em torno de um efeito positivo de 10 pontos de GINI. A partir do $4^{\circ}$ decil, o aumento da desigualdade parece, monotonicamente, amenizar os efeitos positivos da democracia até o ponto que essa gradativa suavização cruza o valor zero (a linha referencial do efeito nulo) e o efeito da democracia sobre a desigualdade torna-se negativo.

Resumindo, de acordo com o resultado do Gráfico 14, a democracia aumenta a desigualdade de maneira substancial entre os países-anos mais iguais e após certo nível de desigualdade seus efeitos positivos são arrefecidos monotonicamente, até que nos países-anos mais desiguais da amostra os seus efeitos tornam-se verdadeiramente negativos.

Este padrão encontrado está de acordo com a narrativa político-econômica a respeito dos efeitos da democratização no Leste Europeu e na América Latina. Enquanto naqueles países mais iguais do mundo, recém-saídos da experiência comunista-soviética, o surgimento da democracia foi acompanhado de um substancial aumento da desigualdade econômica, na América Latina - a região economicamente mais desigual do globo - o esforço do projeto democrático dos últimos 25 anos foi em direção à criação de políticas que reduzam as disparidades econômicas entre os indivíduos.

Este primeiro resultado indica, portanto, que: 1) a relação entre democracia e desigualdade não deve ser tratada 
como homogênea e nem seus efeitos são monotônicos ao longo da distribuição da desigualdade; 2) existe uma relativa homogeneidade dos efeitos da democracia no início da distribuição de desigualdade, e só apenas quando um país-ano atinge níveis intermediários de desigualdade é que a democracia passa a ter seus efeitos positivos amenizados; e, por fim, 3) é apenas no final da distribuição que a democracia age de maneira mais contundente na redução da desigualdade, o que parece indicar um limiar básico a partir do qual a competição política democrática passa a ter como tema principal a efetiva redução da desigualdade econômica.

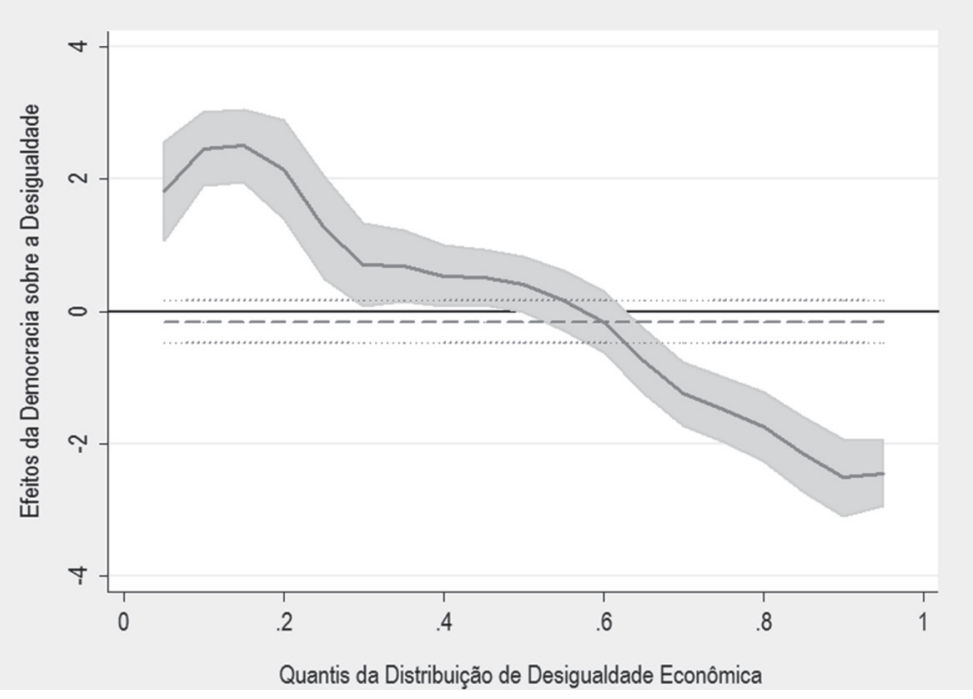

Gráfico 15 - Efeitos heterogêneos da democracia sobre a desigualdade econômica - efeitos fixos continentais e temporais Fonte: CGV e UTIP-EHII

No Gráfico 15 repetimos a mesma estimação, mas agora usando a segunda especificação com efeitos fixos continentais 
e efeitos temporais para o controle de choques exógenos. $\mathrm{O}$ vetor de variáveis controles permanece o mesmo. O gráfico corrobora o anterior, demonstrando que mesmo com a adição de dummies de ano, os efeitos da democracia sobre a desigualdade são fundamentalmente heterogêneos e a abordagem tradicional que assume efeitos homogêneos é equivocada. Contudo, ainda que o formato seja muito semelhante, o Gráfico 15 apresenta algumas diferenças a respeito dos patamares dos efeitos estimados. O primeiro ponto é que nesta especificação o efeito médio da democracia sobre a desigualdade é nulo, uma vez que o seu intervalo de confiança cruza o zero do eixo vertical. Já os efeitos negativos da democracia sobre a desigualdade não são exclusivos apenas dos $13 \%$ países-anos mais desiguais. A partir do $57^{\circ}$ centil (ou os $43 \%$ países-anos mais desiguais), os efeitos da democracia sobre a desigualdade são em direção à criação de uma sociedade cujos recursos são mais homogeneamente distribuídos entre os cidadãos.

Ademais, o ponto de estabilidade inicial dos efeitos positivos da democracia sobre a desigualdade abrange apenas os primeiros $20 \%$ países-anos mais iguais de toda a amostra (os dois primeiros decis da distribuição). A partir do intervalo entre o $2^{\circ}$ e o $3^{\circ}$ decil, os efeitos positivos da democracia em relação à desigualdade começam a ser amenizados monotonicamente até que, próximo ao $6^{\circ}$ decil, a linha do efeito nulo é atravessada e a democracia começa a operar em direção à redução da desigualdade. Os maiores efeitos negativos estão mais uma vez nos limites finais da distribuição, mas a magnitude é reduzida de - 7 pontos de GINI para apenas - 2.5 pontos.

Contudo, apesar das diferenças de magnitudes e valores, as 3 conclusões permanecem respaldadas: 1) a relação entre democracia e desigualdade é heterogênea e seus efeitos não 
variam monotonicamente em toda a distribuição da desigualdade; 2) existe uma relativa homogeneidade dos efeitos da democracia no início da distribuição; e, por fim, 3) é apenas entre os países mais desiguais que a democracia age de maneira mais contundente na redução da desigualdade.

Finalmente, expandimos os controles da especificação, incluindo agora efeitos fixos regionais junto aos efeitos fixos temporais. O Gráfico 16 apresenta o resultado desta estimação. $\mathrm{O}$ vetor de controles permanece o mesmo e o vetor de instrumentos é o apresentado na coluna (5) da Tabela 10. Novamente os mesmos padrões empíricos são encontrados, indicando a veracidade da hipótese de os efeitos da democracia sobre a desigualdade serem heterogêneos e apenas nas sociedades mais desiguais a democracia opera da forma vislumbrada pelos filósofos políticos do século XIX: um sistema que traduz a igualdade política em uma busca por maior igualdade econômica.

O Gráfico 16 corrobora os anteriores, demonstrando que mesmo com a adição de região às dummies de ano, os efeitos da democracia sobre a desigualdade são fundamentalmente heterogêneos e a abordagem tradicional que assume efeitos homogêneos é equivocada. Contudo, ainda que o formato seja semelhante, algumas diferenças são importantes. Em primeiro lugar, a magnitude dos efeitos é menor, variando entre +1 no início da distribuição à -2 no final. Ademais, a estabilidade dos efeitos positivos da democracia sobre a desigualdade no início da distribuição se estende do $1^{\circ}$ ao $4^{\circ}$ decil, mas em uma magnitude bastante menor: um efeito de +0.3 pontos de GINI. 


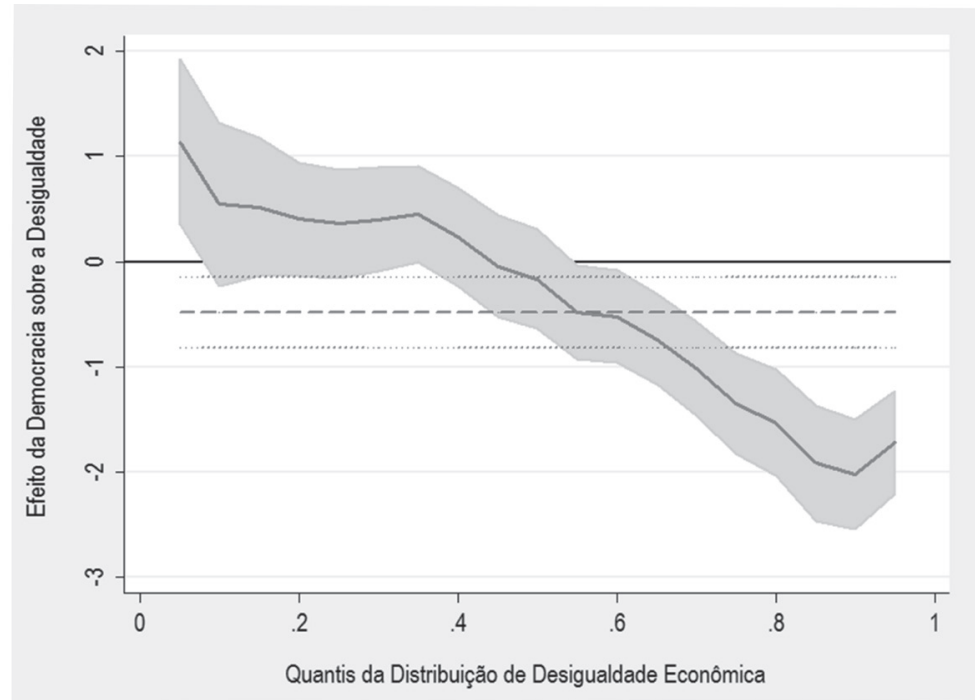

Gráfico 16 - Efeitos heterogêneos da democracia sobre a desigualdade econômica - efeitos fixos regionais e temporais Fonte: CGV e UTIP-EHII

Os efeitos negativos da democracia sobre a desigualdade não são exclusivos apenas dos $13 \%$ ou $43 \%$ países-anos mais desiguais. Os efeitos tornam-se negativos (ainda que nesse ponto da distribuição estatisticamente não diferente de zero) no centil $45^{\circ}$, indicando que para mais de metade dos anos-países da amostra a democracia é uma instituição redutora da desigualdade econômica. E outra vez apenas no final da distribuição que os efeitos da democracia são mais fortes, atingindo -2 pontos de GINI.

Outra constatação surpreendente e bastante distinta dos dois resultados anteriores refere-se ao fato que o efeito médio estimado da democracia sobre a desigualdade na especificação com efeitos fixos regionais e temporais é negativo e significante (próximo de -0.5). Interessante observar que na especificação 
apenas com efeitos fixos continentais os efeitos médios da democracia são positivos, na segunda com efeitos fixos continentais e temporais os efeitos são nulos e na especificação com efeitos fixos regionais e temporais os efeitos são negativos. Evidências contundentes que boa parte das dificuldades em se resolver as discussões a respeito de quais sejam os verdadeiros efeitos da democracia sobre a desigualdade decorre do pressuposto assaz equivocado que os efeitos da democracia são homogêneos, não sendo necessário contextualizá-los ao cenário socioeconômico sobre o qual a competição política ocorre. Por fim, mais uma vez verificamos que as 3 conclusões elencadas acima se confirmam.

Na Figura 1 apresentamos outros quatro modelos distintos. Selecionamos as especificações com efeitos fixos continentais e com efeitos fixos regionais e temporais (as que possuem no mínimo dois instrumentos identificadores de democracia para cada um dos conjuntos de variáveis de difusão e longitudinais), mas agora mantendo em cada uma das estimações apenas um dos conjuntos de variáveis instrumentais. Não reestimamos essa análise para a especificação com efeitos fixos continentais e temporais, pois nesta apenas a variável horiental atende aos dois requisitos de adequabilidade de um instrumento, enquanto llong está estatisticamente relacionada com EHII.

A Figura 1 apresenta quatro gráficos. Na metade superior estão as especificações com efeitos fixos continentais e na metade inferior as com efeitos fixos regionais e temporais. Ao lado direito do gráfico estão as especificações instrumentalizadas apenas pelas variáveis longitudinais enquanto no lado esquerdo estão aquelas instrumentalizadas pelas variáveis de difusão. Os testes estatísticos indicam que os dois modelos com apenas instrumentos de difusão são fortemente 
identificados com democracia e não correlacionados com desigualdade econômica, atendendo os dois critérios de adequabilidade da estimação por variável instrumento. Por sua vez, nos dois modelos com apenas os instrumentos de longitude, os testes de Kleibergen-Paap não rejeitam a hipótese nula de subidentificação e a variável contínua de longitude llong não atende a hipótese de restrição de exclusão no modelo com efeito fixo continental, o que não torna estatisticamente válidos os resultados destes dois modelos.

Conforme podemos ver, os modelos do lado esquerdo que utilizam apenas as variáveis de difusão apresentam resultados bastante semelhantes aos expostos nos gráficos 14 e 16 . Em ambos podemos tomar as mesmas conclusões de que a relação entre democracia e desigualdade é: 1) heterogênea e seus efeitos não variam monotonicamente em toda a distribuição da desigualdade iguais; 2) existe uma relativa homogeneidade destes efeitos positivos no início da distribuição; e, por fim, 3) é apenas no final da distribuição de desigualdade que a democracia age de maneira mais contundente na redução da desigualdade. Além do mais, os resultados também refletem as magnitudes dos efeitos encontrados. No modelo com efeito fixo continental são estimados efeitos que variam entre $+10 \mathrm{e}$ -9.5 e no modelo com efeitos fixos regionais e temporais são estimados efeitos que variam entre +1 e $-2^{105}$.

\footnotetext{
105 Na apresentação gráfica e na discussão dos resultados efetivos em todos os gráficos e figuras desta pesquisa optamos por analisar os dados apenas entre o $5^{\circ}$ e o $95^{\circ}$ centil da distribuição para evitar que outliers deturpem os resultados. Por outro lado, se estimarmos os efeitos da democracia no último centil da distribuição, os resultados são sensivelmente mais poderosos no modelo com efeitos fixos continentais, onde a democracia reduz no $99^{\circ}$ centil a desigualdade econômica em - 6 pontos de GINI enquanto no modelo com efeitos fixos regionais e temporais os efeitos são matizados e chegam a apenas -1.0 pontos.
} 
Efeitos Fixos Continentais - Instrumentos de Difusão

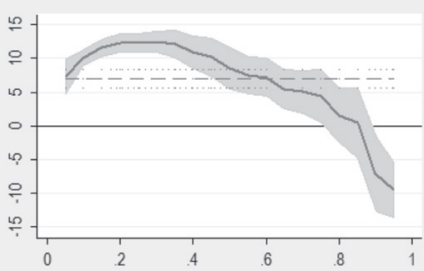

Efeitos Fixos Regionais e Temporais - Instrumentos de Difusão

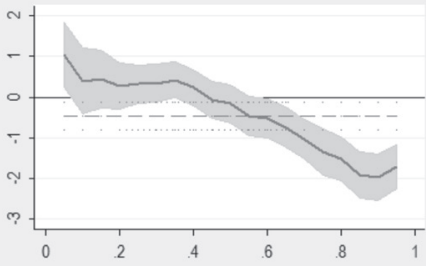

Efeitos Fixos Continentais - Instrumentos de Longitude

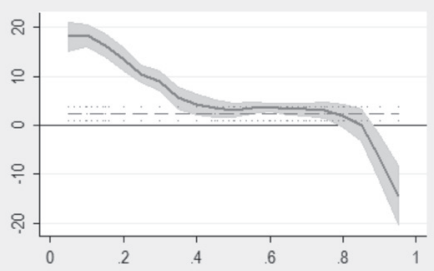

Efeitos Fixos Regionais e Temporais - Instrumentos de Longitude

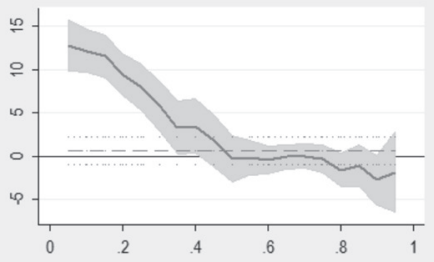

Figura 1 - Efeitos heterogêneos da democracia sobre a desigualdade econômica - diferentes especificações e instrumentos Fonte: CGV e UTIP-EHII

Já nos modelos com apenas instrumentos de longitude (que não identificam adequadamente os efeitos da democracia sobre a desigualdade econômica), algumas das conclusões não são verificadas. Por exemplo, no modelo com efeitos fixos continentais não há mais estabilidade dos efeitos da democracia nos países-anos mais iguais. Esta estabilidade é encontrada entre os países-anos medianamente desiguais. Por outro lado, os efeitos continuam sendo heterogêneos e não monotônicos e a democracia só reduz a desigualdade nos países-anos mais desiguais. Já no modelo com efeitos fixos regionais e temporais a democracia aumenta a desigualdade de maneira contundente nas sociedades mais iguais, mas os efeitos são monotonicamente decrescentes até se atingir a mediana da distribuição de 
desigualdade, onde a democracia passa a ter efeitos que são negativos homogêneos mas não estatisticamente diferentes de zero (isto é, o intervalo de confiança perpassa a linha horizontal de efeito nulo).

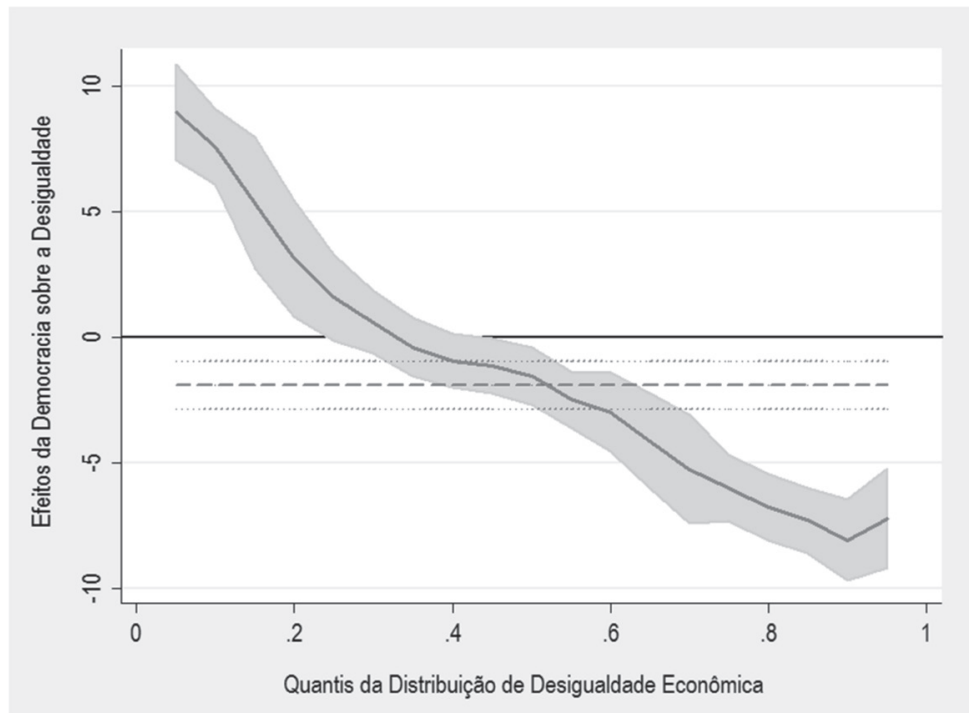

Gráfico 17 - Efeitos heterogêneos da democracia sobre a desigualdade econômica - sem efeitos fixos Fonte: CGV e UTIP-EHII

No Gráfico 17 introduzimos outra especificação da relação entre democracia e desigualdade desta vez sem qualquer controle regional, continental ou temporal. Esta é a especificação mais simples de toda a análise, pois excluí quaisquer tipos de efeitos fixos transversais ou temporais. Sublinhamos que para tal refizemos os passos feitos na seção anterior e usamos apenas os instrumentos que devidamente identificam democracia ao atenderem aos dois critérios necessários para a adequabilidade de um instrumento: a) estar fortemente relacionado 
com a variável endógena e b) não ser correlacionado com a variável dependente e, por consequência, com o termo de erro $\boldsymbol{\varepsilon}_{\mathrm{it}}$ do $2^{\circ}$ passo (hipótese de restrição de exclusão). Nesta análise usamos como instrumentos apenas as variáveis de difusão mundial e regional, difmundo e difregião.

Os resultados apresentados no Gráfico 17 mais uma vez reafirmam e confirmam a hipótese de que os efeitos da democracia sobre a desigualdade econômica são heterogêneos e afetados pelo contexto socioeconômico, no qual ocorre a competição política e eleitoral, sendo positivos entre as sociedades mais iguais e negativos entre as sociedades mais desiguais. Contudo, diferentemente dos achados dos modelos anteriores, a heterogeneidade dos efeitos parece variar de maneira monotônica conforme se amplia a desigualdade econômica. Não há na curva dos efeitos nenhuma aparente estabilidade. Por fim, mais uma vez se confirma a hipótese de que ao final da distribuição de desigualdade que a democracia age de maneira mais contundente para reduzir a desigualdade econômica, ainda que desde o $35^{\circ}$ centil os efeitos da democracia sobre a desigualdade sejam negativos. Mas é exatamente no $9^{\circ}$ decil que o efeito negativo é de maior magnitude: -8 pontos de GINI.

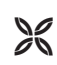

Após analisarmos todas as especificações para avaliar a relação e os efeitos heterogêneos da democracia sobre a desigualdade usando os dados do CGV e do EHII, iremos a partir de agora testar o quanto estes resultados empíricos resistem a diferentes formas de se analisar a relação e mesmo à alteração das medidas de desigualdade e de democracia. Nesta seção finalizamos a análise com a adoção de diferentes intervalos de 
tempo como unidade básica de análise. E na seção seguinte introduzimos os dados do POLITY IV, SIID, SWIID e do BM-GINI e verificamos se a relação encontrada permanece.

Um importante ponto a ser discutido é que de agora em diante não apresentamos os resultados dos testes do $1^{\circ}$ passo das próximas especificações. Contudo, de antemão enfatizamos que todo e qualquer modelo apresentado nas próximas seções possuem instrumentos que atendem aos dois critérios necessários para a validade da estimação por variável instrumental. Isto significa que tiveram resultados satisfatórios nos testes subidentificação e de fraca identificação de Kleibergen-Paap e nos testes de Wald para verificar se o instrumento é correlacionado de maneira significativa com democracia e se é não correlacionado com desigualdade, ambas decisões consideradas a $10 \%$ e a $5 \%$ de significância. Caso não encontremos nenhum conjunto de instrumentos que atenda aos critérios, não apresentamos aquela especificação e justificamos em quais testes os instrumentos falharam.

As primeiras especificações que não atendem aos critérios da metodologia de variável instrumental são aquelas que possuem apenas efeitos fixos regionais ou apenas temporais. Para ambas não encontramos um único conjunto de instrumentos que atendesse aos dois requisitos. Em quase todos ou a hipótese nula de não identificação não foi rejeitada a $10 \%$ ou algum dos instrumentos inclusos não eram estatisticamente significantes. E na única lista de instrumentos no qual a hipótese de não identificação foi rejeitada - os instrumentos difmundo e difcont com efeitos fixos temporais - os instrumentos não atenderam à condição de restrição de exclusão. 


\subsubsection{0 problema dos dados faltantes}

Um terceiro desafio desta pesquisa decorre do fato que utilizamos dados observáveis e que não são sempre compilados pelos países e instituições de pesquisa, impedindo que as conclusões obtidas com o arcabouço regressional em política comparada se aproximem do potencial inferencial de desenhos de pesquisa mais próximos do ideal experimental. Um dos problemas comuns decorrentes da natureza observacional da pesquisa é a existência de muitos dados faltantes, mesmo após uma criteriosa interpolação de dados. Uma importante consideração a ser feita sobre este ponto é a não independência do problema dos dados faltantes. É possível, por exemplo, que ditaduras divulguem menos dados sobre si mesmo do que democracias, assim como países menos desenvolvidos tendam a produzir menos dados que os países desenvolvidos, além de possuírem economias mais instáveis que tornam suas respectivas contas nacionais menos confiáveis.

Uma técnica amplamente utilizada na literatura para lidar com esse problema é a utilização de intervalos temporais maiores como unidade de análise ${ }^{106}$. É exatamente isto o que faremos nesta seção. Reestimamos a relação entre democracia e desigualdade utilizando como intervalo de dados não o país-ano, mas a média trienal, quinquenal, em uma década e em quinze anos das variáveis para cada país ${ }^{107}$. Contudo, antes de

106 Está estratégia empírica foi feita nos principais estudos que tratam sobre os efeitos da democracia sobre a desigualdade, entre estes apontamos: Timmons (2010), Chong (2003), Reuveny e Li (2003) e Li, Squire e Zou (1998). O custo principal desta estratégia é a redução dos casos para análises inferenciais mais complexas, como as que propomos nessa pesquisa.

107 No banco anual temos 46 unidades de tempo, no trienal 15 unidades e no quinquenal 11. Por sua vez, no banco por décadas temo 5 unidades de tempo e 
estimarmos os novos modelos, verificamos por meio de uma regressão logística quais são os atributos dos países que aumentam a probabilidade da inexistência de dados sobre desigualdade econômica.

A coluna (2) da Tabela 12 apresenta os resultados de um modelo logístico que tem como variável dependente principal um indicador que demonstra se o dado sobre desigualdade econômica mensurado pelo EHII é faltante. Os dados que foram interpolados na amostra analisada são considerados como não faltantes. $\mathrm{O}$ modelo deixa claro que a existência de variáveis missing não é aleatória. Nesta coluna (2) apresentamos quais são possíveis determinantes da não divulgação de informações usando como lastro os países-anos. Os países não democráticos [chga_demo] têm 1.70 mais chances de ter a variável desigualdade não reportada. Além do regime político, o nível educacional da população masculina [ihme_ayem], o nível de desenvolvimento [lrgdpc] e o tamanho do Gasto Público [lgsg] também estão negativamente associados com a não divulgação de informações sobre desigualdade, enquanto a abertura comercial [lopenk] e o papel do consumo no PIB [lcsg] estão associados de forma positiva.

Nas colunas (4) a (8) apresentamos a proporção de dados faltantes em cada uma das regiões e continentes analisados e como essa proporção é razoavelmente reduzida nos bancos de dados com intervalos de tempo maiores. Por exemplo, enquanto no banco de dados com intervalo de tempo anual

no banco com intervalo de 15 anos somente 3. Ficando claro que o preço a ser pago por estratégias deste tipo é uma redução da alavancagem inferencial dos dados. Muita informação é perdida neste processo de agregação, o que fica evidente que nos dados mais agregados em 10 e 15 anos os intervalos de confiança tornam-se maiores. 
55\% dos casos africanos são faltantes, essa proporção se reduz para $38 \%$ no banco com intervalo de tempo de 15 anos. Já na América, Ásia e em toda a amostra a redução de informações faltantes é de aproximadamente 15 pontos percentuais. As diferenças são menores para a Europa e a Oceania, justamente os continentes para os quais temos mais e menos informação, respectivamente.

Na Figura 2 usamos essas diferentes amostras e apresentamos os efeitos da democracia sobre a desigualdade ao longo da distribuição da variável dependente por intervalos de tempo trienais, quinquenais, por décadas e a cada quinzena de anos. Como método de identificação utilizamos as mesmas regras das seções anteriores para a identificação do conjunto de instrumentos mais adequados. Optamos por apresentar os dados na especificação apenas com efeitos fixos continentais, uma vez que já houve grande perda da variância dos dados com as agregações realizadas, sobretudo nas análises com intervalos de tempo de 10 anos e 15 anos. Contudo testamos os mesmos modelos para a especificação com efeitos fixos continentais e temporais e os resultados são bastante semelhantes. Sempre incluímos as variáveis instrumentais que identificam fortemente democracia sem ao mesmo tempo estarem relacionadas com desigualdade. 
Tabela 12 - Dados faltantes de desigualdade econômica

\begin{tabular}{|c|c|c|c|c|c|c|c|}
\hline $\begin{array}{l}\text { M. } \\
\text { Logístico }\end{array}$ & $\begin{array}{l}\text { Painel } \\
\text { Anual }\end{array}$ & (3) & (4) & (5) & (6) & (7) & (8) \\
\hline \multirow[t]{2}{*}{ chga_demo } & $-0.63^{\star * *}$ & Missings & $\begin{array}{l}\text { Ano - } \\
\text { pais }\end{array}$ & 3 anos & 5 anos & $\begin{array}{c}10 \\
\text { anos }\end{array}$ & $\begin{array}{c}15 \\
\text { anos }\end{array}$ \\
\hline & 0.07 & & & & & & \\
\hline \multirow[t]{2}{*}{$\operatorname{lrgdpc}$} & $-0.25^{\star * *}$ & África & $55.3 \%$ & $50.8 \%$ & $52.3 \%$ & $44.4 \%$ & $37.9 \%$ \\
\hline & 0.05 & $\begin{array}{l}\text { Af. Norte } \\
\text { e Oriente } \\
\text { Médio }\end{array}$ & $41.8 \%$ & $39.4 \%$ & $41.1 \%$ & $32.3 \%$ & $30.3 \%$ \\
\hline \multirow[t]{2}{*}{ wdi_urban } & -0.00 & $\begin{array}{c}\text { Af. } \\
\text { Subsaariana }\end{array}$ & $61.2 \%$ & $55.8 \%$ & $57.2 \%$ & $49.8 \%$ & $29.5 \%$ \\
\hline & 0.00 & & & & & & \\
\hline \multirow[t]{2}{*}{ ihme_ayem } & $-0.14^{\star * \star}$ & América & $44.9 \%$ & $39.8 \%$ & $43.4 \%$ & $36.3 \%$ & $29.3 \%$ \\
\hline & 0.02 & $\begin{array}{c}\text { Am. do } \mathrm{Ne} \\
\text { Central }\end{array}$ & $46.8 \%$ & $40.9 \%$ & $45.6 \%$ & $36.8 \%$ & $30.3 \%$ \\
\hline \multirow{2}{*}{ lgsg } & $-0.60^{* * *}$ & Am. do Sul & $41.1 \%$ & o & $38.9 \%$ & $35.2 \%$ & $27.3 \%$ \\
\hline & 0.06 & & & & & & \\
\hline \multirow[t]{2}{*}{ lopenk } & $0.21^{\star * *}$ & Europa & $25.2 \%$ & $23.9 \%$ & $26.4 \%$ & $21.4 \%$ & $22.8 \%$ \\
\hline & 0.05 & $\begin{array}{c}\text { Europa } \\
\text { Ocidental }\end{array}$ & $17.8 \%$ & $16.0 \%$ & $17.3 \%$ & $13.3 \%$ & $13.0 \%$ \\
\hline \multirow[t]{2}{*}{ lisg } & 0.09 & $\begin{array}{c}\text { Eur. Orien. } \\
\text { e URSS }\end{array}$ & $36.2 \%$ & $35.5 \%$ & $37.7 \%$ & $32.5 \%$ & $32.8 \%$ \\
\hline & 0.06 & & & & & & \\
\hline \multirow[t]{2}{*}{$\operatorname{lcsg}$} & $0.43^{\star \star \star}$ & Ásia & $45.7 \%$ & $43.1 \%$ & $43.3 \%$ & $41.5 \%$ & $30.6 \%$ \\
\hline & 0.09 & $\begin{array}{l}\text { Extremo } \\
\text { Oriente }\end{array}$ & $44.9 \%$ & $42.9 \%$ & $41.7 \%$ & $40.0 \%$ & $22.2 \%$ \\
\hline \multirow[t]{2}{*}{ tend } & $0.06^{* * *}$ & Asia do Sul & $45.4 \%$ & $43.9 \%$ & $46.4 \%$ & $43.8 \%$ & $36.7 \%$ \\
\hline & 0.01 & $\begin{array}{l}\text { Sudeste } \\
\text { Asiático }\end{array}$ & $46.4 \%$ & $42.3 \%$ & $40.7 \%$ & $40.0 \%$ & $29.2 \%$ \\
\hline \multirow[t]{2}{*}{ global } & -0.02 & & & & & & \\
\hline & 0.12 & Oceania & $67.0 \%$ & $63.8 \%$ & $68.2 \%$ & $60.8 \%$ & $61.8 \%$ \\
\hline \multirow[t]{2}{*}{ llong } & 0.09 & & & & & & \\
\hline & 0.10 & Total & $45.8 \%$ & $42.3 \%$ & $44.2 \%$ & $38.2 \%$ & $33.1 \%$ \\
\hline \multirow[t]{2}{*}{ con 1} & $-1.53^{\star * *}$ & & & & & & \\
\hline & 0.16 & $\mathrm{~N}$ & 7617 & 3233 & 1727 & 849 & 544 \\
\hline
\end{tabular}




\begin{tabular}{|c|c|c|c|c|c|c|c|}
\hline $\begin{array}{l}\text { M. } \\
\text { Logístico }\end{array}$ & $\begin{array}{l}\text { Painel } \\
\text { Anual }\end{array}$ & (3) & $(4)$ & (5) & (6) & (7) & (8) \\
\hline \multirow[t]{2}{*}{ con 2} & $-0.75^{\star \star \star}$ & & & & & & \\
\hline & 0.17 & & & & & & \\
\hline \multirow[t]{2}{*}{ con3 } & -0.29 & & & & & & \\
\hline & 0.26 & & & & & & \\
\hline \multirow[t]{2}{*}{ con 4} & $-1.08^{* * *}$ & & & & & & \\
\hline & 0.17 & & & & & & \\
\hline \multirow[t]{2}{*}{ cons } & 0.98 & & & & & & \\
\hline & 0.70 & & & & & & \\
\hline $\mathrm{N}$ & 6325 & & & & & & \\
\hline
\end{tabular}
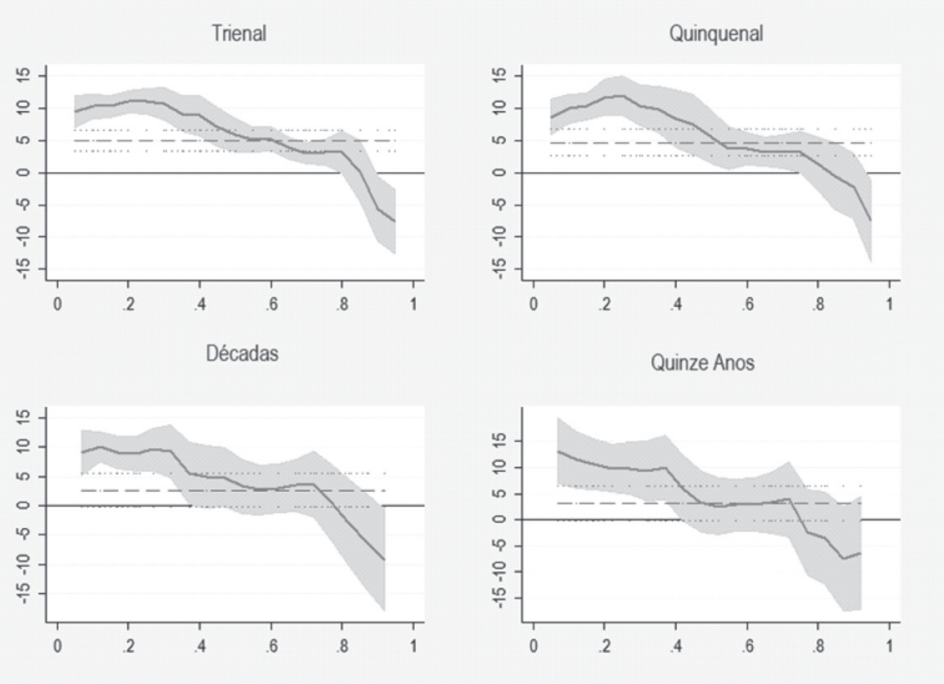

Figura 2 - Efeitos heterogêneos da democracia sobre a desigualdade econômica em diferentes intervalos temporais - efeitos fixos continentais ${ }^{108}$ Fonte: CGV e UTIP-EHII

${ }^{108}$ No modelo com dados trienais foram selecionadas todas as cinco variáveis. Nos outros três modelos - com dados quinquenais, por décadas e com intervalos de 15 anos, excluímos apenas difmundo, pois nestas especificações esta variável não está associada com democracia. 
O formato da curva é bem semelhante em todos os gráficos, independente do intervalo de tempo considerado. De fato os efeitos os efeitos da democracia sobre a desigualdade são mais fortes no sentido de reduzir a desigualdade econômica nas sociedades muito desiguais, sendo, por outro lado, positivos nas sociedades mais iguais. Além disso, nos quatro modelos apresentados na Figura 2 existe um efeito positivo e relativamente homogêneo da desigualdade nos primeiros quatro decis da distribuição de desigualdade, com uma magnitude do efeito semelhante e em torno de 10 pontos de GINI. Isto é a democracia tende a fomentar a desigualdade econômica nos casos mais iguais da amostra.

Entre o $3^{\circ}$ e $4^{\circ}$ decil este efeito positivo da democracia sobre a desigualdade econômica começa a ser amenizado até que por volta do $8^{\circ}$ decil a curva dos efeitos heterogêneos ultrapassa a linha preta contínua, que indica o valor nulo, e os efeitos passam a ser negativos. É somente nos últimos dois decis da distribuição que a democracia produz de fato um efeito negativo sobre a desigualdade e próximo ao $9^{\circ}$ decil o efeito passa a ser máximo, atingindo uma magnitude de -10 pontos negativos. A única ressalva é que no gráfico inferior direito, cujos intervalos são de 15 anos, os erros padrões são bastante grandes e não temos completa confiança estatística no dado estimado. Por outro lado, parece claro que os efeitos negativos da democracia sobre a desigualdade são uma especificidade das sociedades mais desiguais, corroborando os achados empíricos anteriores e a hipótese da heterogeneidade dos efeitos.

\section{$8 \%$}

Ao longo do capítulo entramos na discussão bastante complexa a respeito dos efeitos heterogêneos da democracia 
sobre a desigualdade econômica. Para tal, nos dedicamos, na primeira parte, à análise da adequabilidade do método de variável instrumental para resolver os problemas da potencial causalidade reversa existente na relação entre democracia e desigualdade. Definimos esse problema como potencial, pois existem estudos na literatura que apontam para efeitos completamente diferentes da desigualdade sobre a democracia. Enquanto Acemoglu e Robinson (2006) e Boix (2003) chamam atenção à ameaça redistributiva que a democracia representa às classes dominantes, ao empoderar os desfavorecidos, Ansell e Samuels (2010 e 2014) entendem a chave da democratização como a busca por proteção aos direitos de propriedade de novas elites contra os poderes de um líder autoritário ou de um estado opressor e absolutista.

A seguir demonstramos que as variáveis de difusão e de longitude são instrumentos adequados, pois atendem aos dois critérios básicos para a validade da estimação por variável instrumental: (a) são correlacionados com democracia; e (b) não possuem um efeito causal sobre desigualdade independente dos efeitos da própria democracia. Postas tais condições, podemos assumir com razoável cautela que a associação entre a variação nos instrumentos e a variação em desigualdade deve, de fato, ser atribuída aos próprios efeitos da democracia sobre a desigualdade. $\mathrm{E}$ assim temos confiança estatística para estimar os efeitos da democracia livres da influência que a própria desigualdade exerce sobre os regimes políticos.

Para encontrar evidências empíricas em relação ao primeiro critério foram realizados séries de testes estatísticos em cada uma das especificações e só foram aceitas as variáveis instrumentais que apresentaram bons resultados em todos. Desta forma, temos razoável grau de certeza que o conjunto de 
instrumentos propostos nesta pesquisa identificam fortemente democracia, evitando os graves problemas decorrentes do uso de instrumentos fracos.

Por outro lado, não existem testes adequados para testar o requisito fundamental imposto pela hipótese de restrição de exclusão. Contudo, além da argumentação de que não há nenhum mecanismo que conecte a longitude de um país com o seu nível de desigualdade interno, assim como a própria difusão de democracia, realizamos alguns testes de Wald que são possíveis de serem realizados em modelos sobreidentificados. E isso foi possível, pois em todas as especificações sobreidentificamos a variável endógena democracia.

Após este longo exercício de identificação, introduzimos uma série de diferentes especificações e análises da relação entre democracia e desigualdade, além de inclusive termos apresentados modelos que estimam essa relação em bancos de dados com cortes temporais mais amplos (Figura 2). A série de gráficos apresentada deixa claro que a relação entre democracia e desigualdade não deve em hipótese alguma ser reduzida a um efeito homogêneo. Há evidências fortíssimas de que os efeitos da democracia sobre a desigualdade variam de acordo com o contexto socioeconômico no qual a competição política ocorre.

Ademais, com exceção apenas do gráfico 17, que estima a relação entre democracia e desigualdade sem incluir nenhum efeito fixo, a variação dos efeitos da democracia parece não ser monotonicamente variada ao longo da distribuição de desigualdade. Em boa parte das estimações, foi indicado um efeito positivo da democracia sobre a desigualdade nas sociedades mais iguais que tendia a ser estável ao longo dos primeiros dois ou quatro decis da distribuição. E apenas quando a democracia ocorre em níveis intermediários de desigualdade, 
esses efeitos positivos começavam a ser minimizados até que nos últimos quatro decis da desigualdade se tornavam negativos e seu ponto de maior contundência se localizava entre os dois ou mesmo no último decil da distribuição.

Assim, retomando as duas hipóteses apresentadas no capítulo 2:

H1: As democracias possuem em média um efeito negativo sobre a desigualdade.

H2: Os efeitos negativos da democracia sobre a desigualdade são maiores nas sociedades mais desiguais e tendem a ser menos relevantes em sociedades mais iguais.

Podemos concluir que a Hipótese 2 encontra forte respaldo nos dados. Parece não restar dúvidas que os efeitos da democracia sobre a desigualdade econômica tendem a ser negativos nas sociedades mais desiguais do que nas sociedades iguais, onde de fato, encontramos evidências robustas que os efeitos são positivos. Isto é, a democratização de uma sociedade igual leva a um posterior crescimento da desigualdade operado pelo próprio sistema político.

Por outro lado, em relação à Hipótese 1, dada a existência destes efeitos heterogêneos da democracia sobre a desigualdade que atravessam o eixo dos efeitos nulos, não está claro qual é o efeito médio da democracia sobre desigualdade. Em todos os gráficos analisados incluímos uma linha que indica a magnitude e os erros padrões dos efeitos médios. Em algumas das especificações, como, por exemplo, aquelas com efeitos fixos continentais, o efeito médio da democracia sobre a desigualdade é positivo. Já em outra, a especificação com efeitos fixos continentais e temporais, o efeito médio é nulo, sendo 
equilibrado pelos efeitos negativos em sociedades desiguais e os efeitos positivos em sociedade iguais. $\mathrm{E}$ ainda, outras especificações, como a sem nenhum tipo de efeito fixo ou inclusive outras com efeitos regionais e temporais, o efeito médio da democracia foi negativo.

Esta inconsistência dos achados sobre o efeito médio da democracia sobre desigualdade resulta do fato que a suposição da homogeneidade dos efeitos é extremamente equivocada. É de fundamental importância teórica e empírica a contextualização dos efeitos da democracia sobre a desigualdade de acordo com as condições socioeconômicas nas quais os partidos políticos competem pelo voto popular, incluindo como calculam o custo benefício da obtenção do apoio político eleitoral dos segmentos mais desfavorecidos da sociedade e a existência ou não de uma demanda por redistribuição pela cidadania.

Diante deste rol de evidências, concluímos que os efeitos da democracia são heterogêneos e que nas sociedades mais desiguais é de fato um regime político que reduz com contundência a desigualdade econômica entre os cidadãos. Por outro lado, o arcabouço teórico desenvolvido no capítulo 2 não fornece todas as pistas para explicar o achado empírico que em sociedades mais igualitárias a democracia tende a aumentar a desigualdade econômica, ainda que, historicamente, os efeitos estejam relacionados a transição política nos antigos países sob a esfera de influência da URSS e a democratização destas sociedades tenha sido concomitante ao esforço de diferenciação dos indivíduos com o fim da organização da vida econômica via planejamento central. A ausência de uma clivagem redistributiva implicaria de maneira mais imediata em um não efeito da democracia sobre a desigualdade, mas o que encontramos de maneira consistente ao longo dos diversos modelos foi um efeito positivo da democracia. Desta maneira, parece 
existir a partir dos dados analisados um mecanismo por meio do qual a competição política produz mais desigualdade que as ditaduras em sociedades mais igualitárias.

Finalmente, devido ao fato que existem algumas polêmicas e discussões a respeito das diferentes maneiras de se mensurar democracia e desigualdade, no próximo capítulo testamos a robustez destes achados, analisando a relação entre democracia e desigualdade em outros bancos de dados que cobrem o mesmo horizonte temporal e em um horizonte histórico que abrange todo o processo de democratização do mundo desenvolvido e em desenvolvimento, ainda que o custo da maior abrangência temporal seja a própria qualidade dos dados. 